\title{
Review
}

Cerebrovascular Diseases
Cerebrovasc Dis 2013;36:1-5

DOI: $\underline{10.1159 / 000352050}$
Received: March 14, 2013

Accepted: April 30, 2013

Published online: July 30, 2013

\section{The ASCOD Phenotyping of Ischemic Stroke (Updated ASCO Phenotyping)}

\author{
P. Amarenco ${ }^{a} \quad$ J. Bogousslavsky ${ }^{b} \quad$ L.R. Caplan ${ }^{c}$ G.A.Donnan ${ }^{d}$ M.E. Wolfe \\ M.G. Hennerici ${ }^{\mathrm{e}}$
}

aINSERM U-698 and Paris-Diderot Sorbonne University, Department of Neurology and Stroke Center, Bichat University Hospital, Paris, France; ${ }^{b}$ Center for Brain and Nervous System Diseases, Genolier Swiss Medical Network, Valmont-Genolier, Glion-sur-Montreux, Switzerland; 'Beth Israel Deaconess Medical Center, Division of Cerebrovascular Stroke, Boston, Mass., USA; ${ }^{\text {}}$ Florey Institute of Neuroscience and Mental Health, University of

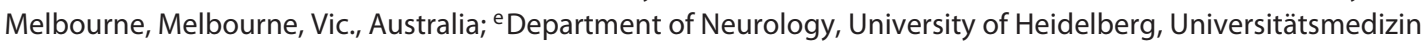
Mannheim, Mannheim, Germany

\section{Key Words}

Stroke etiology and classification · Stroke subtype

\begin{abstract}
ASCO phenotyping (A: atherosclerosis; S: small-vessel disease; C: cardiac pathology; O: other causes) assigns a degree of likelihood of causal relationship to every potential disease ( 1 for potentially causal, 2 for causality is uncertain, 3 for unlikely causal but the disease is present, 0 for absence of disease, and 9 for insufficient workup to rule out the disease) commonly encountered in ischemic stroke describing all underlying diseases in every patient. In this new evolution of ASCO called ASCOD, we have added a ' $D$ ' for dissection, recognizing that dissection is a very frequent disease in young stroke patients. We have also simplified the system by leaving out the 'levels of diagnostic evidence', which has been integrated into grades 9 and 0 . Moreover, we have also changed the cutoff for significant carotid or intracranial stenosis from $70 \%$ to more commonly used $50 \%$ luminal stenosis, and added a cardiogenic stroke pattern using neuroimaging. ASCOD captures and weights the overlap between all underlying diseases present in ischemic stroke patients.
\end{abstract}

(c) 2013 S. Karger AG, Basel

\section{KARGER}

(c) 2013 S. Karger AG, Basel

1015-9770/13/0361-0001\$38.00/0

E-Mail karger@karger.com

www.karger.com/ced

\section{Introduction}

In 2009, we proposed a new system to phenotype patients with ischemic stroke, called ASCO (A for atherosclerosis; $\mathrm{S}$ for small-vessel disease, $\mathrm{C}$ for cardiac pathology, and $\mathrm{O}$ for other causes) to better describe the overlap between diseases underlying a cerebral ischemic event in a stroke patient [1]. Previous stroke subtype classification only considered size and location of cerebral infarction (Oxford classification) or the disease deemed to be directly causally related to the ischemic stroke, neglecting other underlying diseases not deemed to be causally related, although present, such as TOAST and CCS classifications [2].

Based on experience with ASCO during the past few years [3-12], we now propose an updated version called ASCOD phenotyping.

\section{Methods of ASCOD Phenotyping}

In ASCOD, every patient should be graded into 5 predefined phenotypes: A (atheroclerosis); S (small-vessel disease); C (cardiac pathology); $\mathrm{O}$ (other cause), and $\mathrm{D}$ (dissection). As done in the former ASCO classification [1], three degrees of causality between the index ischemic stroke and each category are considered (table 1).
Prof. Pierre Amarenco, MD

Department of Neurology and Stroke Centre, Bichat University Hospital 46, rue Henri Huchard

FR-75018 Paris (France)

E-Mail pierre.amarenco@bch.aphp.fr 
Table 1. Method of classification

\begin{tabular}{ll}
\hline Grades of diseases \\
1 & If the disease is present and can potentially be a cause \\
2 & If the disease is present, but the causal link is uncertain \\
3 & If the disease is present, but the causal link is unlikely \\
0 & If the disease is absent \\
9 & If the workup is insufficient to grade the disease
\end{tabular}

Table 2. Grades of predefined ASCOD phenotypes

\begin{tabular}{l} 
A: Causality grades for atherothrombosis \\
\hline A1 (potentially causal) \\
Atherothrombotic stroke defined as: \\
(1) ipsilateral atherosclerotic stenosis between 50 and $99 \%$ in an intra- or extracranial artery supplying the ischemic field; or \\
(2) ipsilateral atherosclerotic stenosis $<50 \%$ in an intra- or extracranial artery with an endoluminal thrombus supplying the \\
(3) mobile thrombus in the aortic arch; or \\
(4) ipsilateral arterial occlusion in an intra- or extracranial artery with evidence of underlying atherosclerotic plaque \\
A2 (causal link is \\
$\begin{array}{ll}\text { uncertain) } & \text { (1) ipsilateral atherosclerotic stenosis } 30-50 \% \text { in an intra- or extracranial artery supplying the ischemic field; or } \\
\text { A3 (causal link is } & \text { (1) aortic plaque } \geq 4 \text { mm without mobile lesion } \\
\text { unlikely, but the } & \text { (2) aortic plaque <4 mm without mobile thrombus; } \\
\text { disease is present) } & \text { (3) stenosis (any degree) or occlusion in a cerebral artery not supplying the infarct area (e.g. contralateral side or opposite } \\
& \text { (4) history of myocardial infarction, coronary revascularization or peripheral arterial disease; }\end{array}$ \\
(5) ipsi- or bilateral atherosclerotic stenosis 50-99\% with bihemispheric MR-DWI lesion
\end{tabular}

A0 (atherosclerosis not detected)

(1) extracranial arterial stenosis: one or several of the following diagnostic tests are performed and are negative: US-Duplex, CTA, MRA, XRA, or autopsy;

(2) intracranial arterial stenosis: one or several of the following diagnostic tests are performed and are negative: US-TCD, MRA, CTA, XRA, or autopsy;

(3) aortic arch atheroma: TEE with specific assessment of the aortic arch (when the probe is pulled back at the end of the cardiac examination, turn the probe counter clockwise and take time to watch the aortic arch) or specific aortic arch assessment with CTA

A9 (incomplete workup)

US-Duplex, US-TCD or CTA, or MRA, or XRA or autopsy not performed. [A minimum workup is extra- and intracranial assessment of cerebral arteries - maximum workup also includes transesophageal assessment of the aortic arch (or a default CTA of the aortic arch)]

\section{S: Causality grades for small-vessel disease}

S1 (potentially causal) Combination of:

(1) lacunar infarction: small deep infarct $<15 \mathrm{~mm}$ (in perforator branch territory) on MRI-DWI (or a default CT) in an area corresponding to the symptoms and at least one of the three following criteria:

(2) one or several small deep older infarct(s) of lacunar type in other territories, and/or

(3) severe (confluent - Fazekas III) leukoaraiosis, or microbleeds, or severe dilatation of perivascular spaces ('état criblé);

(4) repeated, recent ( $<1$ month), TIAs attributable to the same territory as the index infarct

S2 (causal link is uncertain)

(1) only one, recent, lacunar infarction and no other abnormality on MRI (or CT) or

(2) clinical syndrome suggestive of a deep branch artery stroke, without ischemic lesion in the appropriate area seen on MRI or CT

(main clinical syndrome suggesting a deep branch artery - lacunar - stroke: pure hemiparesis, pure hemisensory loss, ataxic hemiparesis, dysarthria-clumsy hand syndrome, unilateral sensorimotor deficit, others: hemichorea, hemiballism, pure dysarthria, etc.)

S3 (causal link is unlikely, but the disease is present)
Severe (confluent - Fazekas III) leukoaraiosis visible on MRI and/or CT scan, and/or microbleeds visible on T2*-weighted MRI, and/or severe dilatation of perivascular spaces (visible on T2-weighted MRI), and/or one or several old, small deep infarcts of lacunar type 
Table 2 (continued)

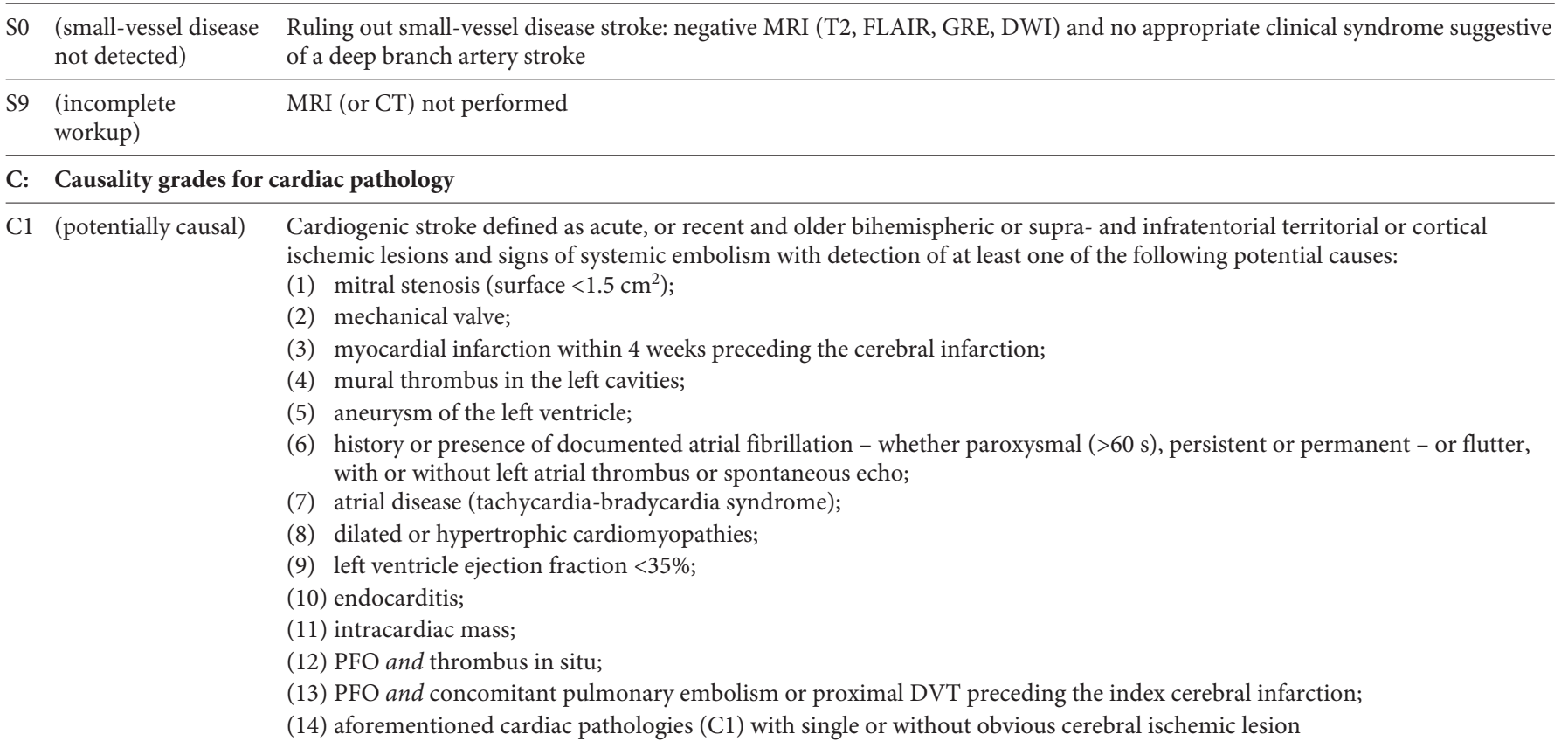

C2 (causal link is Regardless of stroke pattern:

uncertain) (1) $\mathrm{PFO}+$ atrial septal aneurysm;

(2) PFO and pulmonary embolism or proximal DTV concomitant but NOT preceding the index cerebral infarction;

(3) intracardiac spontaneous echo-contrast;

(4) apical akinesia of the left ventricle and decreased ejection fraction (but $>35 \%$ );

(5) history of myocardial infarction or palpitation and multiple brain infarction, repeated either bilateral or in two different arterial territories (e.g. both anterior and posterior circulation);

(6) no direct cardiac source identified, but multiple brain infarction, repeated either bilateral or in two different arterial territories (e.g. both anterior and posterior circulation) and/or evidence of systemic emboli: renal or splenic or mesenteric infarction (on CT, MRI or autopsy) or embolism in peripheral artery supplying arm or leg

C3 (causal link is One of the following abnormalities present in isolation: PFO, ASA, strands, mitral annulus calcification, calcification aortic unlikely, but the disease is present)

C0 (cardiac pathology Ruling out a cardiac source of embolism: minimum is negative ECG and examination by a cardiologist; maximum is negative not detected or ECG/telemetry/24-hour Holter ECG/long-term ECG recording (implantable device, transtelephonic ECG, loop recorder) and not suspected) negative TEE for atrium, valves and septal abnormalities, negative TTE for PFO and assessment of left ventricle, negative cardiac CT/MRI, negative abdominal CT/MRI (search for old or simultaneous subdiaphragmatic visceral infarction)

C9 (incomplete Minimum is ECG and examination by a trained cardiologist in the absence of cardiac imaging workup)

O: Causality grades for other causes

O1 (potentially causal) (1) dolichoectasia with complicated aneurysm;

(2) polycythemia vera or thrombocytemia $>800,000 / \mathrm{mm}^{3}$;

(3) systemic lupus;

(4) disseminated intravascular coagulation;

(5) antiphospholipid antibody syndrome (including >100 GPL units or lupus anticoagulant);

(6) Fabry's disease;

(7) coexisting meningitis;

(8) sickle cell disease;

(9) ruptured intracranial aneurysm with or without vasospasm of the artery supplying the infarcted area;

(10) severe hyperhomocysteinemia;

(11) Horton's disease;

(12) other cerebral inflammatory or infectious angiitis;

(13) moyamoya disease, etc.... 
Table 2 (continued)

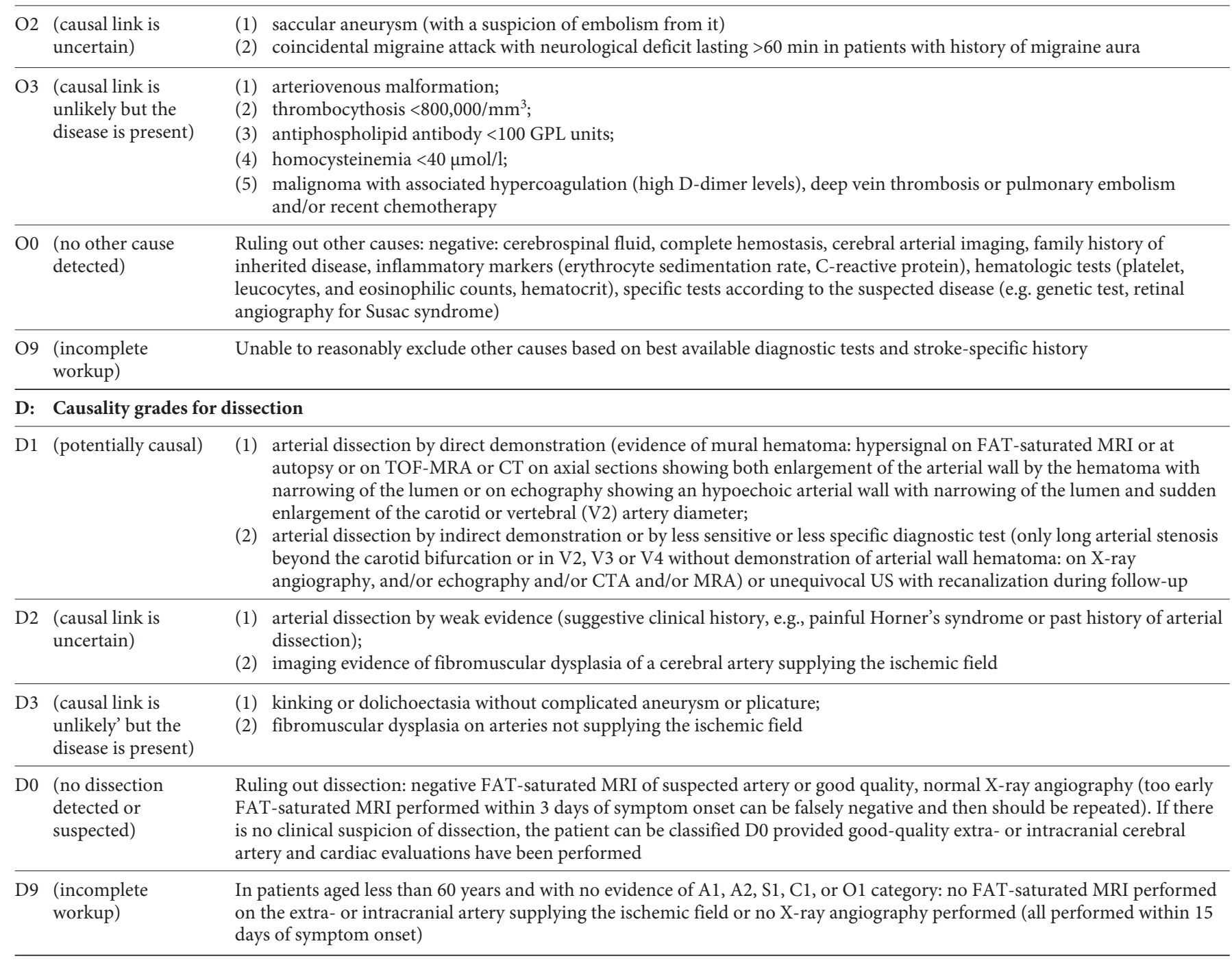

To determine the degree of causality, a number of diagnostic tests must be performed. These diagnostic tests are detailed for each category in table 2 . If the disease is not detected after a minimum workup has been performed, the grade is 0 . In case of incomplete workup (e.g. a minimal workup has not been performed) to rule out the disease, the grade is 9 (tables 1,2 ).

\section{Results}

In this updated version now called ASCOD phenotyping, we have added a ' $D$ ' for dissection, recognizing that dissection is a very frequent causal disease in young ischemic stroke patients. We have also simplified the grading system by leaving out the 'levels of diagnostic evidence'.
This has caused some modifications with regard to technical issues including brain imaging findings, in particular concerning grades C and D. 'Levels of evidence' has now been integrated into grade 9 defined as insufficient workup for each category (table 2). Technical limitations (e.g. poor bone windows for US-TCD or inability to perform MRI) are not necessarily in conflict with full workup. For grade 0 (disease is absent), a separate definition states what is needed to rule out the disease (table 2).

We have also modified the cutoff for significant carotid and intracranial stenosis, from $70 \%$ in the previous ASCO, to the more commonly accepted 50\% luminal stenosis [13] in ASCOD as well as introduced some additional diagnostic and technical requirements.
Cerebrovasc Dis 2013;36:1-5
DOI: $10.1159 / 000352050$
Amarenco/Bogousslavsky/Caplan/ Donnan/Wolf/Hennerici 


\section{Discussion}

ASCOD describes all 5 main diseases underlying ischemic stroke that are present or not in a given patient.

Compared to other stroke-subtyping classifications that categorize ischemic stroke in rigid groups into known cause of stroke and undetermined or cryptogenic stroke, ignoring other underlying diseases not deemed to be causally related, ASCOD grades all diseases present in a given patient, captures the overlap between the diseases, and weights the potentially causal relationship between every disease detected and the ischemic stroke [3-7].

By considering every specific disease underlying the ischemic stroke, ASCOD allows a comprehensive analysis of cohorts of patients with ischemic stroke, particularly for the purpose of clinical trials, phenotype-genotype analyses, or evaluation of the pertinence of a new diagnostic test or a new biomarker. ASCOD may help analyze clinical trials and perhaps select patients in future randomized trials.
One of the main advantages of the ASCOD phenotyping is the lack of an 'undetermined' or 'cryptogenic' group or 'embolic stroke of unknown source' (that could also be named 'embolic stroke of undetected potential sources'). These categories in causative classification systems are too 'cryptic', too difficult to define (in fact they are only 'negatively' defined) and differ from one neurologist or general practitioner to another, which is frustrating for the patients. With the ASCOD system, the only message to the patient is a positive one. In a patient who has no ASCOD 1 category, we can say that we found specific diseases (grades 2 or 3 ), but that we are unable to establish a direct causal relationship between these diseases and the ischemic stroke. However, we can treat these diseases according to guideline recommendations to reduce the risk of recurrence.

\section{References}

$>1$ Amarenco P, Bogousslavsky J, Caplan LR, Donnan GA, Hennerici MG: A new approach to stroke subtyping: the A-S-C-O (phenotypic) classification of stroke. Cerebrovasc Dis 2009;27:502-508.

-2 Amarenco P, Bogousslavsky J, Caplan LR, Donnan GA, Hennerici MG: Classification of stroke subtypes. Cerebrovasc Dis 2009;27: 493-501.

$>3$ Wolf ME, Sauer T, Alonso A, Hennerici MG: Comparison of the new ASCO classification with the TOAST classification in a population with acute ischemic stroke. J Neurol 2012;259: 1284-1289.

$\checkmark 4$ Chatzikonstantinou A, Wolf ME, Hennerici MG: Ischemic stroke in young adults: classification and risk factors. J Neurol 2012;259: 653-659.

5 Chatzikonstantinou A, Krissak R, Schaefer A, Schoenberg SO, Fink C, Hennerici MG: Coexisting large and small vessel disease in patients with ischemic stroke of undetermined cause. Eur Neurol 2012;68:162-165.
6 Wolf ME, Sauer T, Hennerici MG, Chatzikonstantinou A: Characterization of patients with recurrent ischaemic stroke using the ASCO classification. Eur J Neurol 2013;20:812-817.

7 Sirimarco G, Lavallée PC, Labreuche J, Meseguer E, Cabrejo L, Guidoux C, Klein IF, Olivot J-M, Abboud H, Adraï V, Kusmierek J, Ratani S, Touboul P-J, Mazighi M, Steg PG, Amarenco P: Overlap of diseases underlying ischemic stroke: the ASCOD phenotyping. Submitted.

-8 Marnane M, Duggan CA, Sheehan OC, Merwick A, Hannon N, Curtin D, Harris D, Williams EB, Horgan G, Kyne L, McCormack PM, Duggan J, Moore A, Crispino-O’Connell G, Kelly PJ: Stroke subtype classification to mechanism-specific and undetermined categories by TOAST, A-S-C-O, and causative classification system: direct comparison in the North Dublin population stroke study. Stroke 2010;41:1579-1586.

9 Larrue V, Berhoune N, Massabuau P, Calviere L, Raposo N, Viguier A, Nasr N: Etiologic investigation of ischemic stroke in young adults. Neurology 2011;76:1983-1988.
10 Shang Wy, Liu Jy: Stroke subtype classification: a comparative study of ASCO and modified TOAST. J Neurol Sci 2012;15;314:66-70.

11 Cotter PE, Belham M, Martin PJ: Towards understanding the cause of stroke in young adults utilising a new stroke classification system (A-S-C-O). Cerebrovasc Dis 2012;33: 123-127.

12 Amort M, Fluri F, Weisskopf F, Gensicke H, Bonati LH, Lyrer PA, Engelter ST: Etiological classifications of transient ischemic attacks: subtype classification by TOAST, CCS and ASCO - A pilot study. Cerebrovasc Dis 2012; 33:508-516.

13 von Reutern GM, Goertler MW, Bornstein NM, Del Sette M, Evans DH, Hetzel A, Kaps M, Perren F, Razumovky A, von Reutern M, Shiogai T, Titianova E, Traubner P, Venketasubramanian N, Wong LK, Yasaka M, Neurosonology Research Group of the World Federation of Neurology: Grading carotid stenosis using ultrasonic methods. Stroke 2012;43: 916-921. 